Acta Crystallographica Section E

Structure Reports

Online

ISSN 1600-5368

Andris J. Liepa, ${ }^{\mathrm{a} *}$ Saba Jahangiri, ${ }^{a}$ Gary D. Fallon, ${ }^{\text {b }}$ Craig M. Forsyth ${ }^{\mathrm{b}}$ and Andrew C. Warden $^{\mathrm{a}}$

${ }^{a}$ CSIRO Molecular and Health Technologies, Bag 10 Clayton South, Victoria 3169, Australia, and ${ }^{\mathbf{b}}$ School of Chemistry, Monash University, Wellington Rd., Clayton, Victoria 3800,

Australia

Correspondence e-mail: andy.liepa@csiro.au

\title{
7-(Piperidin-1-yl)-2-propyl-4-oxa-5-thia-1,6,7a-tri- azaindene 5,5-dioxide, a derivative of a new ring system. Corrigendum
}

In the paper by Liepa, Jahangiri, Fallon, Forsyth \& Warden

Received 23 January 2007 [Acta Cryst. (2006), E62, o4470-04472], there is an error in the Accepted 26 January 2007 reaction scheme. The correct scheme is given below.

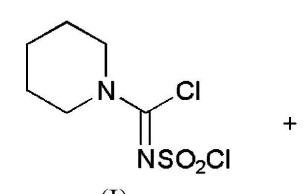

(I)<smiles>CCCC1=NNC(=O)C1</smiles>

(II)

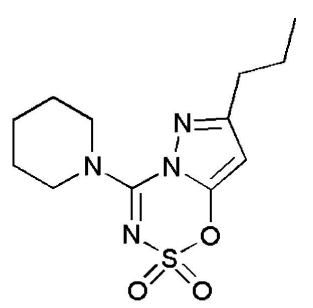

(III) 